\title{
Pluralismo y libre Competencia en el mercado de la televisión y radiodifusión: el caso chileno
}

\section{Pluralism and free competition in the television and radio broadcasting market: the Chilean case}

\author{
Anguita Ramírez, P. y Labrador Blanes, M. J. ${ }^{1}$ \\ Recibido: 27-09-2018 - Aceptado: 16-01-2019 \\ DOI: https://doi.org/10.26441/RC18.1-2019-A1
}

\begin{abstract}
RESUMEN: El estudio ${ }^{2}$ analiza el régimen constitucional y legal aplicable al mercado de los medios de comunicación social en Chile sujetos a concesión estatal y las decisiones elaboradas por las entidades encargadas de velar por la libre competencia en operaciones de venta y adquisición. La investigación, según la evidencia obtenida, destaca en sus conclusiones, la insuficiencia de dicha institucionalidad en la regulación adecuada de un mercado especialmente relevante para el ejercicio de la libertad de expresión en el contexto de una sociedad democrática.
\end{abstract}

Palabras clave: libre competencia; pluralismo; medios de comunicación; regulación; mercado.

ABSTRACT: The study analyzes the constitutional and legal regime applicable to the market of social media in Chile subject to state concession and the decisions made by the entities in charge of ensuring free competition in sales and acquisition operations. The research, according to the evidence obtained, highlights in its conclusions, the insufficiency of said institutionality in the adequate regulation of a market especially relevant for the exercise of freedom of expression in the context of a democratic society.

Keywords: free competition; pluralism; media; regulation; market.

\section{Introducción}

Con el advenimiento del siglo XXI se inició el debate sobre la regulación del mercado de los medios de comunicación social, que en los dos siglos de vida independiente de los países que forman América Latina, apenas se había plan- teado. Con la reimplantación progresiva de la democracia en las naciones del continente se comienza a abordar el pluralismo y la concentración del mercado medial en la región. (Mastrini y Becerra, 2017). La regulación de dicho mercado, estrechamente vinculado a la

1 Pedro Anguita Ramírez es Doctor en Derecho de la Información por la Universidad Complutense de Madrid y profesor de los cursos Derecho de la información, Derecho y publicidad y Derecho y comunicación audiovisual en la Facultad de Comunicación de la Universidad de los Andes (Chile). panguita@uandes.cl, http://orcid. org/0000-0002-6414-7912

Maria José Labrador Blanes es Doctora en Ciencias de la Información por la Universidad Complutense de Madrid y profesora de los cursos Realización audiovisual, Guion audiovisual y Seminario de Investigación Periodística en la Facultad de Humanidades, Escuela de Periodismo de la Universidad Mayor (Chile). maria. labrador@umayor.cl, http://orcid.org/0000-0001-6093-7936

2 El artículo es parte del proyecto el VIII Concurso de Estudios sobre Pluralismo en el Sistema Informativo Nacional 2016, código PLU 160004, Comisión Nacional de Investigación Científica y Tecnológica, (CONICYT). 
libertad de expresión, posee ciertas complejidades al requerir de una concesión estatal del espectro radioeléctrico -bien escaso- para poder operar. En EE.UU., en varios países europeos y entes supranacionales, como la Unión Europea, hace ya años que comenzaron el debate sobre principios y reglas en la asignación de concesiones de radio y televisión, de los límites a la concentración empresarial medial, y de los subsidios que aminoren los defectos y barreras que tiene el mercado audiovisual (Fortin, 2011). La propiedad y control de los medios de comunicación están fuertemente vinculados a la libertad de expresión, por lo que una inadecuada regulación termina por debilitar dicha libertad y afectar el funcionamiento del sistema democrático, al restringir el libre flujo de información e ideas en la sociedad, perjudicando a toda la ciudadanía (UNESCO, 2017). La regulación del mercado de los medios de comunicación en América Latina, luego de la ola democratizadora ha sido conflictiva en varios países, pues el proceso de reforma de la industria medial se ha dado en el contexto de conflicto político entre gobiernos y grupos empresariales propietarios de empresas informativas. Así ha ocurrido en Argentina, Bolivia, Venezuela y Ecuador. Un estudio poco explorado en la región ha sido abordar la regulación del mercado de los medios, desde los principios y normas que regulan la libre competencia. Tal es la perspectiva que aplicaremos en esta investigación.

La escasez del espectro radioeléctrico, que ha sido la justificación más po- derosa para la regulación estatal, se ha visto, sin embargo, alterado por la digitalización de la televisión y la radio y el desarrollo de Internet. Noruega fue el primer país del mundo en programar el termino de las concesiones radioeléctricas para las radios FM, iniciado en enero del año 2017, lo que podría suponer, el fin próximo de las emisiones por dicha frecuencia. La iniciativa del país escandinavo procuró ampliar los canales de radiodifusión y mayor diversidad de contenidos. La televisión de pago -de cable y satelital- también experimenta importantes transformaciones. Ha surgido una tendencia conocida en Estados Unidos como «cord cutting», que da cuenta del retiro masivo de clientes -en especial, de la televisión de cable- en favor de plataformas de Internet como Netflix, Hulu y YouTube. Si bien dicha tendencia aún no ocurre en Chile, ni otros países de la región -la penetración en el país de suscriptores de la televisión de pago por cada 100 habitantes ha pasado de 6,22 (XII.2006) a 17,96 (III.2018) (Subtel., 2018)- merece especial atención, pues lo que ocurre en Estados Unidos suele replicarse en otras naciones del mundo; las innovaciones descritas, deberán estar presente sin duda, en la discusión de los cambios regulatorios futuros.

En el caso de Chile, el mercado de la televisión y radiodifusión, aunque existen algunas reglas, no constituye en rigor, un auténtico marco regulatorio. Una de tales normas introducidas el año 2001, dispuso el deber de los propietarios o controladores de los medios de comunicación sujetos a 
concesión estatal, de contar con un informe favorable de la Fiscalía Nacional Económica, institución encargada de promover y defender la libre competencia, respecto a todo hecho o acto relevante vinculado a la modificación o cambio en la propiedad o control. Desde la entrada en vigor de dichas normas, la Fiscalía Nacional Económica, en adelante la FNE, ha elaborado casi 700 informes. Por tal motivo resulta relevante, analizar las resoluciones, informes y fallos, infiriendo, principios y reglas, y eventualmente una doctrina, que el sistema de libre competencia haya elaborado a fin de evaluar la eficacia del control de la libre competencia. Si en el régimen normativo vigente en el país, el pluralismo se asocia a la competencia que promueve el mercado, el estudio propuesto resulta esencial y útil para evaluar, la posible eficacia del control de la libre competencia respecto a las operaciones relevantes en la propiedad y control de las empresas de televisión y radiodifusión. Dicho resultado, además podría ser útil para instituciones como el Consejo Nacional de Televisión que comenzó el año 2014 a tener competencia para resolver denuncias por infracción al principio del pluralismo.

\section{Metodología}

La metodología en la investigación fue inductiva. Combinó el análisis dogmático con la doctrina jurídica, especialmente vinculada a la libertad de expresión, a la teoría de los derechos humanos, a los principios y normas que regulan la libre competencia y al mer- cado en que comparecen como oferentes, los medios de comunicación y por otro los ciudadanos, actuando como audiencias. A partir de todos los casos informados por la FNE desde el año 2001 respecto a hechos o actos relevantes relativos al cambio de propiedad o control de los medios de comunicación sujetos a concesión estatal se identificó lo que entiende por competencia, libre competencia y pluralismo.

El análisis se extendió a las resoluciones, informes y fallos relevantes que las instituciones nacionales han dictado respecto a operaciones referidas a la propiedad de medios de comunicación sujetos a concesión estatal. El estudio intentará extraer o inferir alguna línea o doctrina, la cual debería ser la base para una futura regulación normativa vinculada a la libre competencia en el mercado informativo.

Lo anterior se concretó a partir de:

- Observación, estudio, captura, transcripción y orden de la información obtenida a través de la FNE y el Tribunal de Defensa de la Libre Competencia, en adelante TDLC.

- Análisis y clasificación de resoluciones, informes y fallos relevantes que las instituciones nacionales han dictado respecto a operaciones relevantes referidas a la propiedad de medios de comunicación sujetos a concesión estatal.

- Derivación inductiva de variados indicadores o tendencias a partir de los hechos más relevantes.

- Adicionalmente la investigación recogió de un modo referencial, fuentes teóricas de literatura 
comparada, para la justificación del pluralismo informativo y me- canismos de protección, especialmente en la Unión Europea.

\section{Mercado de los medios de comunicación sujetos a concesión estatal}

Tabla 1. Concesiones de frecuencias de radiodifusión FM.

Santiago. Área Metropolitana

\begin{tabular}{|c|c|c|c|}
\hline Empresa & Grupo & Radios & $\begin{array}{c}\mathrm{N}^{\circ} \\
\text { concesiones }\end{array}$ \\
\hline Iberoamericana Radio Chile & Prisa (España) & $\begin{array}{l}\text { ADN Radio Chile; Corazón; } \\
\text { Concierto; Imagina; FM Dos; } \\
\text { Pudahuel; Hit 40; Futuro; Rock \& } \\
\text { Pop; Radioactiva y Radio Uno } 1^{3}\end{array}$ & 11 \\
\hline $\begin{array}{l}\text { Producciones Megavisión } \\
\text { Limitada }\end{array}$ & Grupo Beithia & $\begin{array}{l}\text { Candela; Carolina; Romántica; } \\
\text { Infinita; Tiempo }\end{array}$ & 5 \\
\hline Canal 13 & Luksic & Teletrece Radio; Play; Sonar; Oasis & 4 \\
\hline Grupo Radios Dial S.A. & COPESA & Duna, Beethoven, Zero, Disney & 4 \\
\hline $\begin{array}{l}\text { Gestión Regional de } \\
\text { Medios S.A. }\end{array}$ & El Mercurio & Universo & 1 \\
\hline $\begin{array}{l}\text { Radiodifusión El } \\
\text { Conquistador S.A. }\end{array}$ & Cesar Molfino & El Conquistador & 1 \\
\hline Bio Bio Comunicaciones S.A. & Nibaldo Mosciatti & Radio Bío-Bío & 1 \\
\hline $\begin{array}{l}\text { Compañía Chilena de } \\
\text { Comunicaciones }\end{array}$ & $\begin{array}{l}\text { Compañía } \\
\text { Chilena de } \\
\text { Comunicaciones }\end{array}$ & Radio Cooperativa & 1 \\
\hline Publicaciones y Difusión S.A. & $\begin{array}{l}\text { Sociedad } \\
\text { Nacional de } \\
\text { Agricultura }\end{array}$ & Radio Agricultura & 1 \\
\hline Dial Santiago S.A. & $\begin{array}{l}\text { Cámara } \\
\text { Chilena de la } \\
\text { Construcción } \\
\end{array}$ & Pauta FM & 1 \\
\hline Universidad de Chile & $\begin{array}{l}\text { Universidad de } \\
\text { Chile }\end{array}$ & Universidad de Chile & 1 \\
\hline Universidad de Santiago & $\begin{array}{l}\text { Universidad de } \\
\text { Santiago }\end{array}$ & Universidad de Santiago & 1 \\
\hline $\begin{array}{l}\text { Fundación Radio María } \\
\text { Santiago }\end{array}$ & & María & 1 \\
\hline \begin{tabular}{l|} 
Ministerio de \\
Comunicaciones Evangélicas \\
Armonía
\end{tabular} & $\begin{array}{l}\text { Comunicaciones } \\
\text { Radiales } \\
\text { Cordillera S.A. }\end{array}$ & Armonía & 1 \\
\hline $\begin{array}{l}\text { Radiodifusora Romance } \\
\text { Holding Ltda. }\end{array}$ & & La Clave & 1 \\
\hline
\end{tabular}

Fuente: Subtel (n. d.)

\footnotetext{
3 Radio Uno que emitía en frecuencia 97.1 finalizó sus transmisiones el año 2015. El grupo Prisa celebró un contrato de arriendo con un grupo evangélico que transmite radio Corporación en dicho dial.
} 


\section{Televisión}

Tabla 2. Concesionarias de Televisión libre recepción analógicas, banda VHF (última actualización, X. 2018).

\begin{tabular}{|c|c|c|}
\hline Empresa & $\begin{array}{c}\text { Canal de } \\
\text { Televisión }\end{array}$ & $\begin{array}{c}\text { Operador } \\
\text { Usufructuario }\end{array}$ \\
\hline Canal Dos S.A. & Canal 2 & - \\
\hline Cía. Chilena de Televisión & Canal 4 & - \\
\hline P. Universidad Católica de Valparaíso & Canal 5 & $\begin{array}{c}\text { GCO Distribución y } \\
\text { Producciones S.A. }\end{array}$ \\
\hline Televisión Nacional de Chile & Canal 7 & - \\
\hline Red Televisiva Megavisión S.A. & Canal 9 & - \\
\hline Universidad de Chile & Canal 11 & Grupo Turner \\
\hline P. Universidad Católica de Chile (Canal 13 S.A.) & Canal 13 & Grupo Luksic \\
\hline
\end{tabular}

Fuente: Subtel (2018).

\section{Marco referencial}

El pluralismo y su anverso, la concentración del mercado informativo, y el rol de los medios de comunicación, han sido temas de recurrente discusión política e intelectual en el ámbito de la libertad de expresión en Chile. La relevancia del tema ha estado presente desde antes del restablecimiento del sistema democrático, el que se ha prolongado hasta el presente. El segundo gobierno de M. Bachelet (20142018) propuso en su programa de gobierno, la inclusión de una nueva regulación a la libertad de expresión:

Una ley determinará los límites a la concentración de la propiedad de los medios de comunicación social, tanto mono-medial como multimedial, así como la apertura plural del espectro radioeléctrico, y la distribución del avisaje público, de modo de garantizar el pluralismo informativo y el libre acceso a la información (Bachelet, 2013, p. 31).

Terminado su segundo mandato presidencial, la propuesta de regulación al mercado informativo no fue presentada. ${ }^{4}$

No obstante, existen en nuestro país reglas vinculadas a la libre competencia del mercado informativo nacional. La Ley $\mathrm{N}^{\circ} 19.733$ (2001) en su art. 3, si bien no definió pluralismo, expresó, que su

4 Durante el primer gobierno de M. Bachelet (2006-2010), se presentaron el año 2007, dos proyectos de ley, que luego se archivaron. El primero, Boletín 5.644-07, propuso reformar la Constitución Política, introduciendo enmiendas al art. $19 \mathrm{~N}^{\circ} 12$ sobre la naturaleza del espectro radioeléctrico, garantizando el ejercicio de la libertad de expresión y el pluralismo e impidiendo el establecimiento de monopolios en los medios de comunicación. La $2^{\text {a }}$ moción parlamentaria, Boletín 5.474-07, propuso modificar la Ley $N^{\circ} 18.168$ General de Telecomunicaciones, con el objeto de garantizar la libertad de expresión y el pluralismo en medios de comunicación. 
objetivo en el sistema informativo era el favorecer la expresión de la diversidad social, cultural, política y regional del país, para asegurar, la libertad de fundar, editar, establecer, operar y mantener medios de comunicación social. También la Ley $\mathrm{N}^{\circ} 20.750$ que introdujo la Televisión Digital Terrestre y reformó el año 2014 el estatuto legal que regula al Consejo Nacional de Televisión -en adelante CNTV- incorporó el termino pluralismo, dentro de los criterios que forman parte del correcto funcionamiento por el que debe velar el órgano fiscalizador de las emisiones televisivas emitidas en el país. La Ley $\mathrm{N}^{\circ} 20.750$ también añadió una definición de pluralismo, al entenderlo, como el respeto a la diversidad social, cultural, étnica, política, religiosa, género, orientación sexual e identidad de género. Además, la ley reforzó el principio del pluralismo informativo, circunscribiendo al respeto a la diversidad, y exigiendo que su observancia era deber de "los concesionarios y permisionarios de servicios de televisión regulados por esta ley". (art. 1 inc. $5^{\circ}$ letra d) Ley $\mathrm{N}^{\circ} 18.838$ ). Asimismo, la ley agregó la obligación de los concesionarios de respetar el pluralismo en los programas de opinión y debate político, extendido -además- a los noticieros. (art. 14). Según indica la citada ley, el CNTV debe adoptar medidas y procedimientos tendientes a resguardar la observancia de dicho principio en el contexto de la televisión digital. El concepto pluralismo se había incorporado por primera vez a nuestro sistema legal el año 1992, al entrar en vigencia la Ley $\mathrm{N}^{\circ} 19.132$ que fijó el nuevo estatuto de la empresa Televisión
Nacional de Chile. La ley le exigió a la empresa estatal, sujetarse específicamente al pluralismo y a la objetividad en toda su programación y al correcto funcionamiento definido en la Ley $\mathrm{N}^{\circ}$ 18.838, que creó el Consejo Nacional de Televisión.

Pero lo que ha sido más relevante sin duda, además de las reformas legales y del interés de políticos e intelectuales en el debate público sobre la regulación del mercado informativo, fue la incorporación de normas vinculadas a la libre competencia el año 2001 con la entrada en vigencia de la Ley $\mathrm{N}^{\circ} 19.733$ sobre las Libertades de Opinión e Información y ejercicio del Periodismo. Dicha ley incluyó como veremos, dos artículos relacionados con el estatuto legal que regula la libre competencia en el país, contenido básicamente en el D.L. 211 (1973).

\section{1. Constitución Política de la Republica (1980)}

La Constitución Política de la República de Chile, en adelante CPR, en su capítulo III, describe el catálogo de los derechos fundamentales. El art. 19 $\mathrm{N}^{\circ} 12$ asegura a todas las personas la: ...libertad de emitir opinión y la de informar, sin censura previa, en cualquier forma y por cualquier medio, sin perjuicio de responder de los delitos y abusos que se cometan en el ejercicio de estas libertades, en conformidad a la ley, la que deberá ser de quórum calificado.

Dicho inciso fue con cambios accesorios, el contenido en el numeral análogo de la Constitución de 1925. Dicha Carta Fundamental había reproducido 
casi fielmente, lo que, a su vez, había dispuesto la Constitución de 1833 sobre las libertades de información y opinión. No obstante, un antecedente relevante de la extensa regulación -aparte del primer inciso citado- de la CPR de 1980 sobre tales libertades, fue la reforma a la Constitución de 1925 introducida el año 1971, conocida como el Estatuto de Garantías Constitucionales. Dicha enmienda fue la exigencia del partido demócrata cristiano -DC- a la Unidad Popular -UP- para votar en el Congreso Pleno por Salvador Allende como presidente de la república en las elecciones de 1970. Frente al temor del programa de la UP, la DC consensuó con dicha coalición varias enmiendas vinculadas a los derechos fundamentales de los ciudadanos. Una de las libertades más reforzadas fue la libertad de expresión: en primer lugar, dispuso que no podía ser constitutivo de delito o abuso, sustentar y difundir una idea política. Se incorporó además a la Carta Fundamental el llamado derecho de aclaración o rectificación. Se les garantizó a todas las corrientes de opinión el derecho a utilizar medios de difusión y comunicación social de propiedad o uso de particulares. Con todo, el objeto central de la reforma se vinculaba a la propiedad de los medios de comunicación. La enmienda constitucional, por tanto, aseguró a toda persona natural o jurídica, en especial a las universidades y partidos políticos, el derecho a organizar, fundar y mantener diarios, revistas, periódicos y estaciones transmisoras de radio, donde sólo por ley se podría modificar la propiedad y funcionamiento de los medios de comunicación. Además, su expropiación solo podía realizarse por ley aprobada, con quórum de mayoría absoluta en ambas cámaras. Dispuso también, la libertad en la importación y comercialización de libros, impresos y revistas, prohibiendo la discriminación arbitraria entre empresas propietarias de editoriales, diarios, periódicos, revistas, radiodifusoras y estaciones de televisión relativo a venta o suministro de papel, tinta, maquinaria u otros, o autorizaciones o permisos necesarios para tales adquisiciones, dentro o fuera del país.

En la primera referencia a la televisión, la enmienda constitucional de 1971 reservó sólo al Estado y Universidades, el derecho de establecer y mantener estaciones de televisión. Por último, la reforma garantizó la circulación, remisión y transmisión, por cualquier medio, de escritos, impresos y noticias, no opuestos a la moral y buenas costumbres.

Las principales innovaciones que incorporó la Carta Fundamental de 1980 se relacionaron con los principios articuladores vinculados a los medios de comunicación. En primer lugar, dispuso: La ley en ningún caso podrá establecer monopolio estatal sobre los medios de comunicación social. El origen de la norma se explica por la propuesta promovida en el Gobierno de la Unidad Popular de estatizar medios de comunicación privados. Con respecto a la titularidad de la propiedad de los medios de comunicación, la CPR distinguió por una parte a los medios de comunicación impresos, consagrando el derecho de toda 
persona natural o jurídica para fundar, editar y mantener diarios, revistas y periódicos. En cuanto a las empresas de televisión, dispuso que el Estado, universidades y demás personas o entidades que la ley determine podían establecerlas, operarlas y mantenerlas, posibilitando el ingreso a empresas privadas al mercado de la televisión. La Ley Fundamental de 1980 además confirió reconocimiento constitucional al Consejo Nacional de Televisión, órgano fiscalizador que había sido creado el año 1970. En el texto original de la Carta de 1980, la entidad se denominó Consejo Nacional de Radio y Televisión. La reforma constitucional dictada el año 1989 eliminó a la radio del ámbito de competencias de dicha entidad, quedando solo con atribuciones respecto de la televisión. La CPR confirió un carácter autónomo al CNTV, y se asignó el deber de velar por el correcto funcionamiento de los canales de televisión.

De esta forma la CPR de 1980 consagró la libertad de información y opinión, sin referirse a la radiodifusión, al mercado informativo, ni tampoco a la libre competencia y al pluralismo.

\section{El pluralismo en el ordenamiento jurídico nacional}

\subsection{Ley $\mathrm{N}^{\circ} 17.377$ sobre Televisión chilena. (1970)}

El primer estatuto legal que rigió la televisión chilena enumeró taxativamente las entidades que podían establecer, operar y explotar canales de televisión en el territorio nacional. En primer lugar, creó la empresa estatal Televisión Nacional de
Chile, que ya funcionaba, pero que la Ley № 17.377 vino a darle el sustento legal. También incluyó a la llamada televisión universitaria por el legislador, que integraban los canales de televisión dependientes de la Universidad de Chile, Universidad Católica de Chile, y Universidad Católica de Valparaíso, a los que se les exigió que constituyeran una corporación de derecho público, con personalidad jurídica, regida por los estatutos que cada universidad debía dictar, de los que debía tomar razón, la Contraloría General de la República.

El termino pluralismo vinculado al trabajo de los medios de comunicación, apareció el año 1970 por vez primera en Chile, con la dictación de la también primera ley reguladora de la televisión, la Ley $\mathrm{N}^{\circ} 17.377$. El art. $1^{\circ}$ de dicho estatuto, describió los objetivos asignados a la televisión chilena, la que debía

...servir para comunicar e integrar el país; difundir el conocimiento de los problemas nacionales básicos y procurar la participación de todos los chilenos en las grandes iniciativas encaminadas a resolverlos; afirmar los valores nacionales, los valores culturales y morales, la dignidad y el respeto a los derechos de la persona y de la familia; fomentar la educación y el desarrollo de la cultura en todas sus formas; informar objetivamente sobre el acontecer nacional e internacional, y entretener sanamente, velando por la formación espiritual e intelectual de la niñez y la juventud.

A la televisión universitaria, la disposición le encomendó "ser la libre expresión pluralista de la conciencia crítica y del 
pensamiento creador". Por último, la ley dispuso que la "televisión no estará al servicio de ideología determinada alguna y mantendrá el respeto por todas las tendencias que expresen el pensamiento de sectores del pueblo chileno".

El legislador solo le exigió a la televisión universitaria ser la libre expresión pluralista y no a la empresa estatal TVN que por su carácter público debió quedar sometida en forma preferente a tal exigencia. En los hechos, TVN fue desde su creación un medio de comunicación dependiente del gobierno, vinculado jurídica y económicamente al Poder Ejecutivo, no así los canales universitarios, especialmente los vinculados a la Iglesia Católica, que poseían mayores grados de independencia del gobierno. La Ley $\mathrm{N}^{\circ} 17.377$ junto con exigirle pluralismo a la televisión universitaria, no definió dicho término, que tuvo un carácter programático, más que una obligación fiscalizable por el Consejo Nacional de Televisión -en adelante, CNTV-. Además, la potestad sancionatoria de dicha entidad no tipificó entre las conductas sancionables, la obligación del pluralismo exigido a la televisión universitaria. No contempló, por tanto, como después si tuvo la Ley $\mathrm{N}^{\circ} 18.838$ la posibilidad de aplicar sanciones bajo el término "correcto funcionamiento".

De modo que la primera ley sobre la televisión chilena respecto al mercado informativo materializó lo dispuesto por el constituyente, que reservó solo a ciertas universidades y al Estado la operación de canales de transmisión excluyendo a otras instituciones universita- rias y al sector privado. No contuvo tampoco ninguna regla sobre libre competencia, determinando que la responsabilidad derivada de la programación transmitida era indelegable. También se les prohibió ceder a cualquier título sus espacios de transmisión. (art. 31, Ley $\mathrm{N}^{\circ} 17.377$ ). En cuanto a los contenidos obligatorios que debían transmitir los concesionarios, la ley dispuso, con el objeto de contribuir con la cultura política del país, el deber de destinar al menos de 30 minutos semanales a la difusión de espacios, a todos los partidos y movimientos políticos con representación parlamentaria, en condiciones equitativas, para debatir problemas nacionales frente a la ciudadanía. (art. 34, Ley $\mathrm{N}^{\circ}$ 17.377). Fuera de dichos programas, la ley prohibió a los canales de televisión transmitir propaganda política. Por último, la ley determinó que todas las intervenciones del Gobierno por la televisión, para exponer ideas, proyectos o realizaciones, confería a los partidos políticos de oposición el derecho a replicar con igual horario y extensión en proporción a su representación parlamentaria. (Art. 36, Ley $\mathrm{N}^{\circ} 17.377$ ).

\subsection{La Ley $\mathrm{N}^{\circ} 19.733$ sobre Libertad de Opinión e Información y ejercicio del Periodismo. (2001).}

La vigente Ley $\mathrm{N}^{\circ} 19.773$ ha sido la octava ley general reguladora de los medios de comunicación social y del ejercicio del periodismo. Dicho estatuto normativo fue el primero en definir el termino pluralismo. También en fijar formalidades a los medios de 
comunicación en caso de cambios de propiedad, como la de notificar a las instituciones que velan por la libre competencia. Permitió -art. 9 inc. $3^{\circ}$ - el ingreso de sociedades extranjeras a las concesiones de radiodifusión, sujeta al principio de reciprocidad, es decir que los nacionales, tuviesen las mismas condiciones que en el país de origen de los inversionistas foráneos. El iter legislativo de la Ley $\mathrm{N}^{\circ} 19.733$ duró casi 8 años. Se inició el 8 de julio de 1993 y terminó con su publicación el 4 de junio 2001. Una causa de tan prolongada discusión parlamentaria se debió a la dificultad de alcanzar ciertos consensos, como la definición de pluralismo, y la forma de asegurar tal principio en el mercado de los medios de comunicación del país. Hubo una larga discusión sobre cuales debían ser las normas reguladoras del mercado informativo que asegurasen una diversidad en la oferta y también sobre la función que debía desempeñar el Estado en asegurar el pluralismo en la industria medial. El fuerte desacuerdo en tales temas quedó plasmado en el proyecto aprobado en el primer trámite constitucional por la Cámara de Diputados, que en su art. 9 , inc. $1^{\circ}$ dispuso:

El Estado tiene la obligación de garantizar el pluralismo en el sistema informativo, para lo cual habrá de favorecer la coexistencia de diversidad de medios de comunicación social y la libre competencia entre ellos, asegurando la expresión efectiva de las distintas corrientes de opinión, así como la variedad social, cultural y económica de las regiones.
Dicha propuesta normativa, al igual que la norma que sugirió limitar la participación del mercado informativo a los medios de comunicación, fue impugnada por un grupo de legisladores que estimaron que contradecía diversos preceptos de la CPR, lo que abordaremos en el punto 5.2.

\subsection{El Consejo Nacional de Televisión y el pluralismo.}

La Ley $\mathrm{N}^{\circ} 18.838$, en su texto original, confirió al CNTV, en el art. 12 e), la atribución de otorgar, modificar y declarar el termino de las concesiones de radiodifusión televisiva y de servicios limitados de televisión, no así de las concesiones de radiodifusión televisiva de libre recepción. Fue la Ley № 19.131 (D.O. 8 abril 1992), que le dio la competencia al CNTV la competencia para otorgar, renovar, modificar, o declarar el termino de las concesiones de servicios de televisión de libre recepción. Desde que posee tales competencias, el CNTV se ha limitado a efectuar un examen formal de las solicitudes, autorizando todas las transferencias del derecho de usufructo por parte de las universidades de Chile, Católica de Santiago y Valparaíso, que conservaron la nuda propiedad, aunque haya implicado la transformación de la regulación de la televisión de libre recepción sin que haya mediado ninguna reforma legal y menos un debate público sobre tal cambio.

El CNTV posee, además, por mandato legal, la facultad de fiscalizar que los contenidos emitidos por los canales de televisión se adecuen al estándar 
correcto funcionamiento definido en el art. 1 de la Ley $\mathrm{N}^{\circ} 18.838$. La entidad estatal solo comenzó el año 2013 a través de estudios, informes y encuestas, a reflexionar sobre el pluralismo, concepto que se incorporó el año 1992, con la dictación de la Ley $\mathrm{N}^{\circ} 19.131$ (D.O. 8 abril 1992). Dicha ley reformó la Ley $\mathrm{N}^{\circ}$ 18.838 , la que incorporó al pluralismo dentro de los criterios que integran el correcto funcionamiento por el que debe velar el CNTV. La reforma legal también le encomendó al CNTV la adopción de medidas y procedimientos para que en programas de opinión y debate político se respetase el pluralismo. En el periodo 1992-2013, el CNTV no se ocupó del pluralismo. Fue con la aprobación en el año 2014 del proyecto de ley que permite la introducción de la Televisión Digital Terrestre, convertido en la Ley $\mathrm{N}^{\circ} 20.750$ que el CNTV comenzó a darle aplicabilidad al termino pluralismo. Dicha ley definió el pluralismo como "...el respeto a la diversidad social, cultural, étnica, política, religiosa, de género, de orientación sexual e identidad de género...". Además, lo que explica la actividad del CNTV en el campo del pluralismo, fijó a los concesionarios y permisionarios de los servicios de televisión, el deber de observar los principios que integran el correcto funcionamiento, dentro de los cuales, el año 1992 como expresamos, se había añadido el pluralismo. De modo que el CNTV tiene que velar por el pluralismo en la programación de los canales de televisión, sin más orientaciones normativas que la definición transcrita. Luego de cuatro años de vigencia de la norma, el CNTV ha desatendido el deber legal de implementar medidas y procedimientos para que las empresas de televisión respeten el principio del pluralismo. El CNTV ha elaborado investigaciones, encargado estudios, encuestas y opiniones de expertos sobre el pluralismo, pero no se ha traducido en normas generales a las cuales debe sujetarse la industria televisiva. Tal inactividad puede ser visto desde una perspectiva liberal como positivo, pues la industria de la televisión quedaría expuesta a evidentes riesgos al quedar obligada a controles de contenidos, lo que vulneraría, el derecho a la libertad de información asegurado en la Constitución Política y tratados internacionales sobre derechos humanos. Ya se han presentado algunos casos, donde se pueden advertir las amenazas, y que sintetizamos a continuación.

\subsubsection{Formulaciones de cargo a Televisión Nacional de Chile, programa El Informante debate sobre el conflicto en el Medio Oriente.}

El CNTV le formuló cargos a Televisión Nacional de Chile, en adelante, TVN, rol A00-14-1271-TVN, por la emisión del programa El Informante el día 22 de julio del año 2014. El procedimiento se originó con la presentación de ocho denuncias de particulares en contra del programa, que alegaron una vulneración al pluralismo, debido a que no se invitó a representantes de la causa palestina al debate que abordó el conflicto que mantiene dicho país con Israel. Pese a que la Unidad de Supervisión del CNTV estimó que no 
hubo infracción a la norma, la entidad estatal decidió formular cargos, con débiles argumentos, como que el panel del debate carecía de identidad con la causa palestina. (Acta sesión ordinaria, CNTV. 01.12.2014). El mismo CNTV luego de haber presentado cargos, absolvió en su dictamen a TVN, expresando que los invitados al programa $\mathrm{El}$ Informante, eran idóneos y conocedores del conflicto, y que el respeto al pluralismo se determinaba por el contenido de las emisiones y no por el origen o pertenencia a grupos determinados de los invitados o panelistas. El CNTV estimó, por último, que la figura infraccional no estaba suficientemente satisfecha.

\subsubsection{Caso Chilevisión emisión programa En la Mira sobre el proyecto Alto Maipo.}

Este caso posee aun mayor gravedad, pues el CNTV formuló cargos a Chilevisión, en adelante, CHV, y también lo sancionó por emitir el 25 de junio de 2014 el programa "En la Mira", que vulneró el derecho fundamental a la información, integrante del correcto funcionamiento, por haber entregado información incompleta y sesgada sobre el Proyecto Hidroeléctrico Alto Maipo. El CNTV no se pronunció sobre el atentado contra del pluralismo, pues estimó subsumida dicha infracción en la comisión del ilícito contra el derecho a la información, esgrimiendo que no podía sancionarse a un canal dos veces por un mismo hecho. Los fundamentos de la entidad fiscalizadora para sancionar a CHV son absolutamente incompatibles por la libertad de información. El GNTV reprochó la toma de posición de los autores del programa; desequilibrio en la duración de secuencias de los efectos negativos del proyecto; utilización de fuentes no identificadas; "parcialidad de la entrega informativa en la construcción de híbridos argumentales mediante la amalgama de declaraciones con imágenes"; haber omitido la participación del BID y Banco Mundial en el proyecto. (Cons. $19^{\circ}$ ). Concluyó el CNTV que los reparos "privan al reportaje (...) de aquella ecuanimidad inherente a la naturaleza de las entregas informativas de su especie, haciendo decaer la calidad de la entrega informativa (...) al nivel de una mera descalificación" del proyecto (Cons. 20ㅇ). (Dictamen acordado el día 29 de octubre de 2014, ingreso CNTV N 1871/2014). La Corte de Apelaciones de Santiago, causa rol $\mathrm{N}^{\circ}$ 8.635-2014, confirmó la sanción. El tribunal de alzada, al rechazar la apelación deducida por CHV concluyó: (Sexto) que el programa no respetó los estándares que comprende el concepto "correcto funcionamiento", afectando el derecho de las personas a ser debida y correctamente informadas sobre hechos de relevancia; no presentando en concreto un programa televisivo con una visión objetiva, como sostiene la recurrida (...) que presenta las dos visiones, en especial la de las personas involucradas en el mismo, de manera parcial. El fallo tuvo un voto disidente que propuso dejar sin efecto la sanción, al exponer el programa adecuada y equilibradamente distintas visiones del proyecto provoca en la opinión pública, exhibiendo opiniones de los involucrados en forma 
directa, tanto de personas naturales y jurídicas de derecho público concernidas (...) y que la conductora del programa (...) inicie y cierre el mismo, dando su opinión sobre el proyecto, es una cuestión propia del periodismo de opinión (...) y lo propio respecto a exhibir un testimonio reservado la identidad del entrevistado, con amparo en el art. $7^{\circ}$ de la Ley No 19.733. El programa no transgredió para el voto de minoría el "correcto funcionamiento de los servicios de televisión”, y que, dentro de la libertad de opinión, corresponde a toda persona formarse una opinión sobre un tema de interés nacional como el que abordó el programa En la Mira, estándares que cumple el programa referido.

Chilevisión solo pudo eximirse de la sanción, por decisión de la Corte Suprema (C.S., Causa Rol № 6.944/2015). El máximo tribunal de justicia del país en su razonamiento sostuvo que, aunque la sanción no constituía censura previa, prohibida en forma explícita por la Constitución Política, era una medida que interfería en la libertad de emitir opinión y la de informar... de cualquier forma y por cualquier medio, reconocida por su art. $19 \mathrm{~N}^{\circ} 12$ de la CPR. Advirtió la Corte Suprema que dicha libertad comprende tomar y comunicar una determinada posición -primer reproche del CNTV- en que su ejercicio de cualquier forma, determina que el comunicador puede legítimamente juzgar qué información resulta relevante difundir y cómo transmitirla. En la misma línea está el reproche de la declaración del supuesto ingeniero del
Ministerio de Obras Públicas, que oculta su faz y se deforma su voz, que se corresponde con el ejercicio de la libertad para elegir la forma de emitir opinión e informar, compatible con la necesidad de mantener reserva de identidad de la fuente, que es una condición básica del periodismo de investigación.

Para la Corte Suprema,

El ejercicio de estas libertades puede que no garantice la ecuanimidad del programa o que no contribuya en alto grado a la formación de la opinión pública. Pero son la expresión de la convicción constitucional de que dichas libertades, con todas sus limitaciones y alcances, son necesarias para el funcionamiento de una democracia genuina y vigorosa (Cons. $15^{\circ}$ ).

Luego de indicar que la sanción aplicada por el CNTV constituía una interferencia en las libertades señaladas, descartando la comisión de delitos, el máximo tribunal de justicia del país razonó si en la exhibición del programa "En la Mira" emitido por CHV hubo un abuso que justificara la imposición de una sanción fundada en la vulneración "al derecho fundamental a la información que tienen las personas, parte del principio del correcto funcionamiento de los servicios de televisión”. La Corte Suprema no advirtió en el art. $1^{\circ}$ de la Ley $\mathrm{N}^{\circ} 18.838$ una referencia directa a un derecho fundamental a la información, y tampoco su reconocimiento explícito en la CPR. Aunque admitió que el Pacto de San José de Costa Rica reconoce el derecho a la información, como un derecho a buscar y recibir información, como lo 
declaró la Comisión Interamericana de Derechos Humanos (CIDH). (Caso C.R. y otros us. Chile, sentencia de 19 de septiembre de 2006). De modo que para la Corte Suprema no es,

...un derecho que se constituya en un límite a las libertades de emitir opinión y de informar, tal que justifique sancionar determinadas comunicaciones difundidas a través de medios de comunicación social que no satisfagan ciertos estándares de ecuanimidad, objetividad o imparcialidad.

Para la Corte Suprema, la sanción impuesta no tenía justificación en un derecho a la información, motivo por el cual, al imponer dicha sanción, el CNTV “...ha interferido en dichas libertades constitucionales de un modo que no se encuentra autorizado en derecho". (Motivo $16^{\circ}$ ). Añadió la Corte Suprema que, si bien podía ser efectivo que un programa objetivo habría requerido cobertura de opiniones omitidas, la falta de objetividad no justificaba imponer una sanción, no siendo posible justificar jurídicamente la demanda de objetividad en un amplio derecho a la información. (Motivo $19^{\circ}$ ). Concluyó el tribunal, sosteniendo que los ministros que dictaron la sentencia incurrieron en falta al confirmar la sanción, lo que califica de grave, al validar una interferencia no autorizada en el ejercicio de las libertades constitucionales de emitir opinión y de informar. (Motivo $20^{\circ}$ ).

\section{El mercado informativo chileno y la libre competencia}

El ordenamiento constitucional, consagró, como advertimos, una muy bre- ve referencia a la propiedad de los medios de comunicación y al mercado informativo. Las normas legales, también escasas, son las siguientes.

\subsection{La Ley $\mathrm{N}^{\circ} 19.733$ y la libre compe- tencia}

El consenso en torno a una definición de pluralismo fue una de las materias más controvertida en el debate parlamentario que dio origen a la Ley $\mathrm{N}^{\circ}$ 19.733, junto a quien debía asegurarlo, y las reglas reguladoras que debía poseer el mercado de los medios de comunicación. En las intervenciones de parlamentarios y ministros de Estado que participaron en la discusión del proyecto de ley, se sostuvo que en la experiencia internacional existían dos escuelas o teorías. La primera era regular directamente el mercado de medios de comunicación con normas que limitaban el ingreso a la propiedad, ya sea en las empresas informativas, o bien para evitar la propiedad cruzada, esto es, la integración de medios de distintos mercados, de modo que un propietario de radios no pudiese poseer a la vez, un diario o de un canal de televisión. Este modelo aplicado en Europa principalmente impone cuotas máximas de mercados, por venta de ejemplares o ranking de audiencias a los medios de comunicación. La segunda tendencia, era garantizar al máximo la libertad de creación de nuevos medios de comunicación, asegurando fuertemente la libre competencia, bajo normas comunes de la legislación antimonopólica. Esta última, fue la que recogió finalmente la ley aprobada, y que compartió el Poder 
Ejecutivo, la que se impuso al primer modelo. El proyecto de ley elaborado por el presidente de la República a la Cámara de Diputados contenía una disposición que vinculó el mercado informativo a la institucionalidad de libre competencia existente en el país, al ya citado, D.L. $\mathrm{N}^{\circ}$ 211. Para tal efecto, el mensaje presidencial dispuso que se considerarían entre otros, como hechos, actos o convenciones, que tienden a impedir la libre competencia, los que entraben la producción de informaciones, el transporte, la distribución, la circulación, el avisaje y la comercialización de los medios de comunicación, y quienes los ejecuten o celebren incurrirán en la pena establecida en el art. $1^{\circ}$ inc. $1^{\circ}$ del referido cuerpo legal. Para los efectos del inc. $2^{\circ}$ del art. $1^{\circ}$ del DL $N^{\circ}$ 211, de 1973, se reputarán artículos o servicios esenciales los pertinentes a la operación o mantención de los medios de comunicación social. No obstante, la Cámara de Diputados, modificó la propuesta original del Ejecutivo, aprobando un art. 43, que luego pasó al Senado, con las siguientes prohibiciones y limitaciones a la propiedad de los medios de comunicación:

- En el ámbito de la prensa escrita, el control de más del 30\% del mercado informativo nacional en manos de una persona natural o jurídica, sola o asociada con otra u otras; y el control directo o indirecto por una per- sona natural o jurídica, sola o asociada con otra u otras, de más del $30 \%$ de la distribución de los diarios de información general.

- El control de más del 15\% del mercado informativo general por una sola persona natural o jurídica; o de más del 20\% del referido mercado por dos o más personas naturales o jurídicas, asociadas.

- El dominio de dos o más tipos diversos de medios de comunicación social en un mismo mercado, por una persona natural o jurídica, sola o asociada con otra u otras.

La Cámara aprobó una disposición por la cual todo hecho o acto relevante relativo a la modificación o cambio en la propiedad de un medio de comunicación social debía informarse a la Comisión Preventiva Regional o Comisión Preventiva Central, dentro de 30 días de ejecutado.

\subsection{Sentencia del Tribunal} Constitucional sobre el proyecto de ley que regula las libertades de opinión, información y ejercicio del periodismo. $^{5}$

El proyecto de ley aprobado por la Cámara de Diputados fue objeto de un requerimiento por inconstitucionalidad ante el Tribunal Constitucional, en adelante el TC, cuyo cuarto capítulo recayó precisamente sobre las normas que proponían límites a la propiedad de los

5 STC, rol N ${ }^{\circ} 226$, sentencia dictada el 30 de octubre de 1995. Requerimiento formulado por diversos diputados para que el tribunal resuelva sobre la cuestión de constitucionalidad planteada durante la tramitación del proyecto de ley sobre "Libertad de Expresión, Información y ejercicio del Periodismo" de acuerdo al artículo $82 \mathrm{~N}^{\circ} 2$ de la Constitución Política de la República. 
medios de comunicación, así como cuotas máximas fijadas. El TC acogió el requerimiento. Sostuvo que el proyecto vulneraba el derecho a desarrollar una actividad económica lícita, asegurado en el art. $19 \mathrm{~N}^{\circ} 21$ de la CPR. El TC advirtió además una infracción al art. $19, \mathrm{~N}^{\circ} 21,26$ y 24 , pues el inc. $2^{\circ}$ del art. 43 impedían la libre competencia, constituyendo ilícitos penados por el art. $1^{\circ}$, inc. $1^{\circ}$, del D.L. 211. Para el Tribunal Constitucional, impedir la posesión de más del 30\% del mercado informativo nacional de la prensa escrita, o la distribución de diarios de información general, vulneraba el derecho de emprender contenido en el art. $19 \mathrm{~N}^{\circ} 21$. El TC estimó que ninguna de tales circunstancias concurría, pues la actividad que se pretendía impedir no atentaba con dichas limitaciones por tener porcentajes mayores a los dispuesto en el proyecto. El art. 43 también, vulneraba el art. 19, $\mathrm{N}^{\circ} 24$, inc. $2^{\circ}$ de la CPR, pues para el TC, aunque la norma citada permitía limitar al derecho de propiedad, lo autorizaba siempre que derivase de su función social. El TC agregó, que las limitaciones jamás podían afectar el contenido esencial del derecho, privando el derecho, que tiene la propuesta normativa, pues según la Constitución, el legislador no tenía competencia, vulnerando, por tanto, los arts. $6^{\circ}$ y $7^{\circ}$ de la CPR (Cons. 46). El TC concluyó que el precepto impugnado carecía de los elementos esenciales para una restricción, pues el elemento referencial de la norma, era el control de un segmento del mercado informativo o de un porcentual de la distribución de publicaciones, que corresponde a datos eminentemente cambiantes, sujetos a la libre voluntad, decisión y opción de los que compran o adquieren publicaciones, sintonizan emisiones radiales o seleccionan el medio audiovisual. El fallo del TC, a juicio de los críticos de la decisión, clausuró la regulación normativa del pluralismo informativo (Zúñiga, 2008). El fallo del TC y la opinión del Senado y del presidente de la Republica fueron factores decisivos de las normas que acordaron los órganos colegisladores sobre el pluralismo y la libre competencia de los medios de comunicación. La opción adoptada fue entregar la regulación del mercado informativo a las instituciones encargadas de la defensa de libre competencia. Para tal objeto, el texto original de la Ley $\mathrm{N}^{\circ} 19.733$ dispuso una norma sobre la inversión extranjera en la radiodifusión y dispuso el deber de notificación en caso de modificación, cambio o control de medios de comunicación social.

\subsection{Sistema chileno de la libre competencia.}

El estatuto normativo de la libre competencia está contenido esencialmente en el D.L. 211 (D.O. 22 dic. 1973), dictado apenas tres meses luego del Golpe de Estado ocurrido el 11 de septiembre. No obstante, ya la misión de la consultora estadounidense KleinSacks había sugerido en los años 50' que Chile incorporara a su ordenamiento jurídico, normas antimonopolios (COUYOMDJIAN, 2011). El D.L. 211 en lo esencial consagró como delito $\left(\right.$ art. $\left.1^{\circ}\right)$, con pena privativa de libertad, 
todo acto o convención, que tendiese a impedir la libre competencia en la producción o en el comercio interno o externo. La ley, en su art. $1^{\circ}$ inc. $2^{\circ}$, aumentaba en un grado la sanción penal, en caso de que los hechos contrarios a la libre competencia recayesen en artículos o servicios esenciales, tales como, alimentación, vestuario, vivienda, medicinas o salud, rubros que de acuerdo con la redacción de la norma no era taxativa. El D.L. 211 en otra relevante disposición -art. $2^{\circ}$ - enumeró también a vía ejemplar los siguientes hechos, actos o convenciones que tendían a impedir la libre competencia: - Los que se refieran a la producción, tales como el reparto de cuotas, reducciones o paralizaciones de ellas; - Los que se refieran al transporte; - Los que se refieran al comercio o distribución, sea mayorista o al detalle, tales como el reparto de cuotas o la asignación de zonas de mercado o de distribución exclusiva, por una sola persona o entidad, de un mismo artículo de varios productores; - Los referidos a la determinación de los precios de bienes y servicios, como acuerdos o imposición de los mismos a otros. Clausuraba la disposición una norma general que calificaba como contraria a la libre competencia, todo arbitrio que tuviese por finalidad eliminarla, restringirla o entorpecerla. De modo que, adoptada la decisión legislativa de vincular la protección de la libre competencia al mercado informativo, debió la Ley $\mathrm{N}^{\circ} 19.733$ incluir normas adecuatorias. En primer lugar, el art. 37 de la Ley $\mathrm{N}^{\circ} 19.733$ consideró como hechos, actos o convenciones, que tendían a im- pedir la libre competencia, aquellos vinculados con la actividad esencial de los medios de comunicación social: los que entrabasen la producción de informaciones, el transporte, la distribución, circulación, el avisaje y la comercialización de las empresas informativas. En segundo término, el art. 43 reputó como artículos o servicios esenciales los pertinentes a la operación o mantenimiento de los medios de comunicación social, por lo que todo acto contrario a la libre competencia respecto al mercado informativo constituía una figura agravada, sancionada con una pena aumentada en un grado. Por último, la protección de la libre competencia quedó entregada en caso de adquisiciones, ventas o cambios de control de los medios de comunicación, al deber de notificar dichas operaciones a la Comisión Preventiva Regional o Comisión Preventiva Central, según el caso. Dicho régimen de notificación era aplicable solo a los medios de comunicación escritos. Respecto a los medios de comunicación social sujetos a concesión estatal, se exigía aparte de la notificación, el contar con un informe previo a su perfeccionamiento de la respectiva Comisión Preventiva respecto a su impacto en el mercado informativo. Tal informe debía evacuarse dentro de los 30 días de presentada la solicitud, que en caso contrario se entendía que no había objeción alguna.

La Ley $\mathrm{N}^{\circ} 19.911$ introdujo importantes cambios al D.L. N 211 (1973) ordenado y sistematizado por el D.F.L. $\mathrm{N}^{\circ}$ 1 (M. Economía, 2004) principal estatuto con jerarquía de ley sobre la libre 
competencia. Una de las reformas más relevantes fue sustituir las Comisiones Preventivas Regionales y Nacional por el Tribunal de Defensa de la Libre Competencia, que creó dicha ley. Por dicho motivo dicho tribunal pasó a ser el continuador y sucesor de las Comisiones Resolutivas, y por tanto a conocer y resolver un conjunto de materias a que se refieren varias disposiciones legales, entre otras, los arts. 37, 38 y 43 de la Ley $\mathrm{N}^{\circ}$ 19.733. La Ley $\mathrm{N}^{\circ} 19.911$ reemplazó el art. 1 y 2 de dicha ley, despenalizando los actos contrarios a la libre competencia, eliminando la distinción entre conductas recaídas en bienes o servicios esenciales y los que carecían de tal calificación, que tenía importancia al constituir una figura agravada en los atentados contra la libre competencia. La Ley $\mathrm{N}^{\circ} 20.361$ derogó los arts. 37 y 34 de la Ley $\mathrm{N}^{\circ} 19.733$.

Por tanto, desde la entrada en vigor de la Ley $\mathrm{N}^{\circ} 19.733$ el 4 de junio 2001 a la reforma introducida por la Ley $\mathrm{N}^{\circ}$ 19.911 (D.O. 14 nov. 2003) fueron las Comisiones Preventivas, Regionales o Nacional, las que debían recibir las notificaciones de modificación, cambios o control de propiedad. Desde el 14 de noviembre de 2003 dicha función fue asumida por el TDLC solo hasta la dictación de la Ley $\mathrm{N}^{\circ} 20.361$ (D.O. 13 julio 2009) que dispuso que las atribuciones ya descritas, debían realizarla la FNE, lo que se ha mantenido hasta la actualidad.

El mensaje presidencial que se convirtió en La Ley $\mathrm{N}^{\circ}$ 20.361, propuso reemplazar el TDLC por la FNE debido a la carga de trabajo que le daba al tribunal, y a que las conductas que examinaba eran en la mayoría de los casos de escasa trascendencia. De modo que para el Poder Ejecutivo sólo en limitados casos se detectaron conductas susceptibles de identificar con los hechos, actos o convenciones que, según el art. 3 modificado la Ley $\mathrm{N}^{\circ} 19.911$ al DL N 211, podían ser objeto de sanción por el Tribunal. Además, justificó que las modificaciones a los arts. 37 -en rigor su derogación- y 43 de la Ley $\mathrm{N}^{\circ} 19.733$, en que contenían descripciones de conductas orientadas a fijar presunciones legales de los supuestos de hecho previstos en los inc. $1^{\circ}$ y $2^{\circ}$ del art. $1^{\circ}$ del DL $\mathrm{N}^{\circ} 211$, sustituidos por la Ley $\mathrm{N}^{\circ}$ 19.911 .

En síntesis, la regulación propuesta adecuó la Ley $\mathrm{N}^{\circ} 19.733$ al DFL $\mathrm{N}^{\circ} 1$ de Economía, de 2004. Redujo el número de ingresos al TDLC, al entregar al FNE la facultad de determinar los actos susceptibles de atentar contra la libre competencia, radicando en dicha entidad, el examen preventivo de los hechos y actos relevantes relativos a la modificación o cambio en la propiedad o control de un medio de comunicación social.

\subsection{Normas vigentes vinculadas a la} libre competencia en el mercado informativo y la función de la Fiscalía Nacional Económica respecto al mercado de los medios de comunicación.

Según los cambios normativos descritos, la regla legal vigente sobre la libre competencia y el mercado de los medios de comunicación es el art. 38. Tal disposición ordena la notificación de 
todo hecho o acto relevante relativo a la modificación o cambio en la propiedad de un medio de comunicación social a la FNE, dentro de 30 días de su ejecución, medida aplicable a los medios escritos, como diarios, revistas y periódicos. En caso de que tales hechos o actos relevantes sean respecto a medios de comunicación social sujetos al sistema de concesión otorgada por el Estado, deben contar previo a su perfeccionamiento, con un informe de la FNE referido a su efecto sobre la competencia, también debiendo evacuarlo dentro de los 30 días siguientes a la recepción de los antecedentes. En caso que el informe sea desfavorable, el FNE debe comunicarlo al TDLC para efectos de lo dispuesto en el art. 31 del D.F.L. $\mathrm{N}^{\circ} 1$. De no evacuarse el informe dentro del referido plazo, se entenderá que no amerita objeción alguna por parte de la FNE. El TDLC no posee, de acuerdo al texto de la Ley $\mathrm{N}^{\circ} 19.733$ el deber expreso de resguardar el pluralismo, aunque existe una opinión doctrinaria en contra. (Domper y Arancibia, 2007).

Dos cambios importantes se advierten en la reforma al art. 38 dispuesto por la Ley $\mathrm{N}^{\circ} 20.361$. En primer lugar, en el texto original de la Ley $\mathrm{N}^{\circ} 19.733$ las Comisiones Preventivas debían evaluar en los cambios de propiedad de los medios de comunicación sujetos a concesión estatal "su impacto en el mercado informativo". Luego de la modificación introducida por la Ley $\mathrm{N}^{\circ}$ 20.361, la FNE debe evaluar el "efecto sobre la competencia". El segundo cambio, es que en la actualidad existe una consecuencia en caso que el informe de la FNE sea desfavorable, pues en tal caso debe remitir los antecedentes al TDLC, y seguir ante dicho tribunal, un procedimiento no contencioso. La FNE, ha elaborado, por su obligación de elaborar informes de cambios de propiedad de un medio de comunicación sujeto a concesión estatal, un total de 689 hasta julio de 2017. De todos los informes, casi la totalidad ha tenido un informe favorable de la FNE y apenas un conjunto muy reducido ha sido objetado por afectar la libre competencia, que han seguido el procedimiento no contencioso ante el TDLC.

\section{Conclusiones}

El régimen jurídico actualmente vigente y aplicable al mercado de los medios de comunicación es inadecuado. En la práctica no existen reglas mínimas sobre incompatibilidades, prohibición de adquisiciones o controles de medios de comunicación. Existe solo dos normas. La primera -art. 9 inc. $3^{\circ}$, Ley $\mathrm{N}^{\circ}$ 19.733- condiciona el ingreso de capitales foráneos a la propiedad de una emisora de radiodifusión a un tratamiento reciproco o equivalente de chilenos en el país originario de inversionistas extranjeros. La segunda, art. 15 , inc. 11 , Ley $\mathrm{N}^{\circ} 18.838$, impide que el titular de una concesión de televisión pueda obtener otra similar en la misma zona de servicio, con la excepción de Televisión Nacional de Chile.

El Grupo Prisa adquirió doce emisoras de radiodifusión, con sus respectivas concesiones, incumpliendo la condición establecida en el principio de reciprocidad descrito, sin que ninguna 
autoridad administrativa ni judicial, declarase la caducidad de pleno derecho, la sanción que prevé la norma citada.

Un aspecto no consensuado en nuestra doctrina se refiere a la discusión sobre si la libertad de crear empresas -muy limitada en el caso de empresas de radio y televisión- asegura o no asegura el pluralismo, al tratarse de un mercado limitado y no abierto, debido a la escasez del espectro radioeléctrico. Esta singularidad propia de los mercados regulados, no ha sido destacada por las instituciones dedicadas a velar por la libre competencia. Tales entidades deben redefinir indicadores u metodologías para evaluar cuál es el mercado relevante, y apliquen criterios especialmente elaborados para medir la concentración de los mercados de medios de comunicación, utilizados ya hace muchos años en el derecho comparado. El único aplicado en el país ha sido el Herfindahl-Hirschman Index (HHI), baremo de general aplicación en todo tipo de mercados.

En el mercado de la radiodifusión es donde ha habido más diversidad y pluralismo en Chile, situación que en los últimos años ha ido cambiando. Dos grandes holdings empresariales nacionales -Beithia y Luksic- comenzaron en los inicios hace pocos años progresivamente a adquirir medios de comunicación, inicialmente canales de televisión -Mega y Canal 13- lo que se extendió a empresas radiodifusión, lo cual presenta nuevos desafíos para una adecuada regulación.

Según la estructura de propiedad, el mercado de la radiodifusión chilena tie- ne cuatro conglomerados relevantes: Iberoamerican Radio Chile (11): Concierto, Activa, ADN, 40 Principales, Imagina, Pudahuel, Futuro, Rock and Pop, Uno, FM Dos y Corazón; Grupo Luksic (5): Teletrece Radio, Horizonte, Oasis, Play y Sonar; El grupo Bethia (5) luego de adquirir el canal de televisión Megavisión tomó el control de Radio Candela, y luego de las radios Carolina, Romántica, Infinita y Tiempo. Grupo Dial (4): Beethoven, Duna, Disney y Zero; Luego, todas las demás empresas radiales poseen solo una concesión, como la Compañía Chilena de Comunicaciones (radio Cooperativa), Sociedad Nacional de Agricultura (Agricultura), Biobío Comunicaciones (Red Bio-Bío) y la familia Molfino (El Conquistador), entre otros. El grupo Edwards, dueño de la cadena El Mercurio, se ha expandido a regiones con red Positiva FM y Digital FM, también adquirió Universo. Asociaciones gremiales poseen empresas de radiodifusión como la Sociedad Nacional de Agricultura y más recientemente, en el año 2017, la Cámara Chilena de la Construcción. También dos universidades públicas, como la Universidad de Chile y la Universidad de Santiago tienen empresas de radiodifusión en la ciudad de Santiago. La configuración del mercado de la radiodifusión acredita la ineficacia de las escasas reglas que cautelan la libre competencia, como las atribuciones que tiene en dicho campo, tanto la FNE como del TDLC.

La televisión de libre recepción en Chile fue reservada en sus inicios en forma exclusiva al Estado y a las tres 
universidades más importantes del país. Dicho diseño cambió sin reforma legal alguna. Dichas universidades conservaron la titularidad de sus concesiones y la nuda propiedad, traspasando el usufructo y la operación de sus señales, frente a lo cual, las autoridades de la libre competencia no pusieron reparo alguno. Las empresas que actualmente operan los canales de televisión de libre recepción pertenecen al Estado -Televisión Nacional de Chile-; a grupos económicos, -Mega por Grupo Beithia y Canal 13 por el Grupo Luksic- a empresas multimediales extranjeras, Chilevisión por Time Warner; UCV TV por GCO SpA y Telecanal a un conglomerado mexicano, cuya propiedad se ha vinculado a Ángel Gonzalez, según una denuncia en la FNE que se investiga actualmente, pues ya posee la concesión del canal La Red.

Solo en los últimos años, tanto la FNE y el TDLC ha comenzado a abordar más detenidamente las operaciones consultadas. En los primeros años, tales entidades, no le dedicaron mayor estudio a las operaciones consultadas, las que se aprobaban sin mayor análisis. La casi unanimidad de los informes elaborados por la FNE se limitaba a indicar que la operación consultada "no genera efectos adversos al proceso de libre competencia en el mercado", lo que "no alteraría la cantidad de participantes en dicho mercado". Por otra parte, la definición del mercado relevante que utilizan tales entidades es anacrónica, pues evalúa solo la sustitubilidad entre radios FM y AM, soslayando las radios que emiten por
Internet y que no utilizan concesiones de radiodifusión, y a las nuevas audiencias que sintonizan sus preferencias radiales y televisivas que emiten por Internet. En la actualidad, el TDLC ha impuesto condiciones a las operaciones de holdings que operan canales de televisión y radios, como prohibir ventas atadas de publicidad en ambas clases de medios de comunicación y de entregar frases publicitarias gratuitas en sus radios. También se ha regulado la venta conjunta de espacios publicitarios en distintos medios o plataformas, de modo que los espacios publicitarios puedan ser adquiridos en forma separada. Otra medida impuesta ha prohibido discriminaciones arbitrarias, incluyendo subsidios cruzados, contrarios a la libre competencia y se ha exigido separar los negocios de radio y televisión en empresas independientes. Por último, se ha limitado la duración de la cláusula de no competir, pactada a dos años desde la suscripción del contrato.

La falta de regulación específica en el mercado informativo ha hecho que las autoridades dedicadas a velar por la libre competencia no tengan presente, su singularidad y especialidad y la importancia para el funcionamiento general de nuestro sistema democrático. No existe un mandato específico para resguardar el pluralismo. De modo que el examen que suelen efectuar tanto la FNE o el TDLC, tiene presente solo la libre competencia lo que no garantiza la existencia del pluralismo. Pueden existir mercados altamente competitivos lo cual no implica que exista una diversidad y heterogeneidad de propuestas 
mediáticas. Dicho punto, no ha sido abordado por las autoridades de libre competencia. Por último, la función que posee la FNE en informar teniendo presente "el efecto sobre la competencia", en las operaciones consultadas que recaen sobre concesiones en el mercado de radio y televisión luego de la reforma contenida en la Ley $\mathrm{N}^{\circ} 20.361$, no se ha consolidado en un texto que recoja sus criterios interpretativos que sinte- tice y oriente a los intervinientes del mercado.

El estudio se ha limitado al mercado de la televisión y radiodifusión en Santiago (Área Metropolitana) donde se domicilian los principales medios de comunicación del país. Para una adecuada política regulatoria, debería analizarse la libre competencia y el pluralismo del mercado audiovisual en todas las regiones del país.

\section{Bibliografía}

Bachelet, M. (2013, octubre). Programa de Gobierno Michelle Bachelet (2014-2018). Recuperado de: http://www.subdere.gov.cl/sites/default/files/noticias/archivos/programamb_1_0.pdf

Couyomdjian, J. P. (ed.), (2011). Reformas económicas e instituciones políticas: la experiencia de la Misión Klein-Sacks en Chile. Santiago: Universidad del Desarrollo.

Domper, M. y Arancibia, J. (2007). Fusión en el mercado de radiodifusión sonora (GLR Chile Limitada solicita su pronunciamiento al TDLC respecto de la compra de Iberoamerican Radio Chile S.A.). En: Sentencias Destacadas 2007, Libertad y Desarrollo, (345-379).

Fortin, C. (2011). Derecho a la información y propiedad de los medios de comunicación: teoría, normativa comparada, problemática chilena. Revista de Derecho Público, Núm. 75, 2do semestre, 171-241. DOI: 10.5354/0719-5249.2015.36641

Mastrini, G. y Becerra, M. (2017). La concentración Infocomunicacional en América Latina 20002015: nuevos medios y tecnologías, menos actores. $1^{\underline{a}}$ ed. Bernal. Universidad Nacional de Quilmes; Observacom, 2017. Recuperado de: http:/www.unq.edu.ar/catalogo/415-laconcentraci\%C3\%B3n-infocomunicacional-en-am\%C3\%A9rica-latina-2000-2015.php

Mendel, T., García A., y Gómez G. (2017). Concentración de medios y libertad de expresión: Normas globales y consecuencias para las Américas. Montevideo: Cuadernos de Discusión de Comunicación e Información 7, UNESCO.

Subsecretaría de Comunicaciones de Chile (Subtel) (2018). Series suscriptores televisión de pago. Recuperado de: https://www.subtel.gob.cl/estudios-y-estadisticas/television/

Subtel (n. d.). Servicios de Radiodifusión Sonora. Recuperado de: https://www.subtel.gob.cl/inicio-concesionario/servicios-de-telecomunicaciones/servicios-de-radiodifusion-sonora/

Subtel (2018). La Subsecretaria de Telecomunicaciones, solo consigna el titular de la concesión, no las empresas cesionarias que operan en la actualidad la señal de televisión. Recuperado de: https:// www.subtel.gob.cl/inicio-concesionario/servicios-de-telecomunicaciones/ servicios-de-television-abierta/

Zúñiga, F. (2008). Propiedad y control de los medios de comunicación social: algunas notas sobre el estatuto de radiodifusión. Revista Estudios Constitucionales, 6 (1), 171-203. 